\title{
Spectroscopic analysis of embryo culture media for predicting reproductive potential in patients undergoing in vitro fertilization
}

\section{In vitro fertilizasyon hastalarının üreme potansiyelini belirlemede embriyo kültür medyasının spektroskopik analizle incelenmesi}

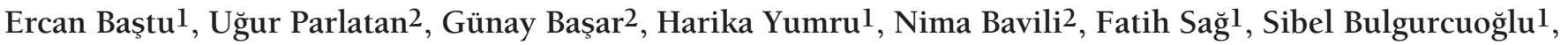
Faruk Buyrul

1İstanbul University İstanbul Faculty of Medicine, Department of Obstetrics and Gynecology, İstanbul, Turkey

2̇ंstanbul Technical University Faculty of Science and Letter, Department of Physics Engineering, İstanbul, Turkey

\begin{abstract}
Objective: To predict the reproductive potential of embryos via Raman spectroscopy evaluation of the spent culture media as well as with a conventional morphologic evaluation.

Materials and Methods: Women of reproductive age $(n=31)$ who were treated for unexplained infertility and scheduled for single embryo transfer were invited to participate in this prospective study. After the embryos were removed from the culture, the spent culture media were stored at - $80{ }^{\circ} \mathrm{C}$ after snapfreezing in liquid nitrogen.

Results: Fifteen patients were clinically pregnant, and 16 patients were clinically non-pregnant. Clinical pregnancy was predicted using Raman spectroscopy in $93 \%$ (14/15) of clinically pregnant patients, and in 62.5\% (10 out of 16) of clinically non-pregnant patients. The sensitivity of the Raman spectroscopic analysis was $93 \%$ and the specificity was $62.5 \%$.

Conclusion: Metabolomic evaluation of spent embryo culture media is an emerging technique with promising objective results. However, there is clearly room for improvement.

Keywords: In vitro fertilization, embryo culture media, morphology, Raman spectroscopy

Öz

Amaç: Embriyoların üreme potansiyelini belirlemede kültür medyasını Raman spektroskopik analizle ve süregelen morfolojik değerlendirmeyle karşılaştırılmasıdır.

Gereç ve Yöntemler: Açıklanamayan infertilite tedavisine göre ve tek embriyo transferi olacak 31 üreme yaşındaki kadın bu prospektif çalışmaya katıldı. Embriyolar kültürden alındıktan sonra, kültür medyası $-80^{\circ} \mathrm{C}$ 'de likit nitrojende donduruldu.

Bulgular: On beş hastada klinik gebelik bulunmuşken, 16 hastada gebelik bulunmamıştır. Klinik gebelik tahmini Raman spektroskopiyle \%93 (14/15), gebe olmayan hastalarda ise \%62,5 (10/16) olmuştur. Raman spektroskopik analizin sensitivitesi \%93, spesifitesi \%62,5 şeklindedir.

Sonuç: Embriyo kültür medyasının metabolomik değerlendirmesi objektif sonuçlar doğurabilir. Öte yandan metodun geliştirilmesi ihtiyacı gerekmektedir. Anahtar Kelimeler: In vitro fertilizasyon, embriyo kültür medyası, morfoloji, Raman spektroskopi
\end{abstract}

Address for Correspondence/Yazışma Adresi: Ercan Baştu, MD,

İstanbul University İstanbul Faculty of Medicine, Department of Obstetrics and Gynecology, İstanbul, Turkey

Phone: +90 5324134195 E-mail: ercan.bastu@istanbul.edu.tr ORCID ID: orcid.org/0000-0003-0810-6195

Received/Geliș Tarihi: 26.01.2017 Accepted/Kabul Tarihi: 06.09.2017

${ }^{\oplus}$ Copyright 2017 by Turkish Society of Obstetrics and Gynecology

Turkish Journal of Obstetrics and Gynecology published by Galenos Publishing House 
PRECIS: Metabolomic evaluation of spent embryo culture media is an emerging technique with promising objective results; however, there is clearly room for improvement.

\section{Introduction}

The identification of embryos with the highest potential to implant and establish ongoing pregnancy is the primary aim in human-assisted reproduction. This task is undertaken every day by embryologists worldwide during the treatment of couples that wish to conceive through in vitro fertilization (IVF). The optimal scenario is the transfer of a single embryo that gives rise to a singleton pregnancy. However, even in patients with good prognosis, namely patients aged under 35 years, implantation and the subsequent success rates are well below the expectations of infertile couples undergoing IVF treatment. Therefore, multiple embryo transfer has become clinical routine in IVF clinics worldwide to increase the rate of pregnancies. This approach has consequences such as an increased rate of multiple gestations, which are regarded as high-risk pregnancies ${ }^{(1)}$. Furthermore, the treatment process may cause considerable emotional, financial, and physical distress for couples undergoing IVF treatment because nearly two out of every three IVF cycles do not result in pregnancy ${ }^{(2)}$. The current limitations in the determination of embryos that have the highest implantation potential probably contribute to the low rates of pregnancy during IVF treatment. Hence, improvement of embryo selection has been a "hot research topic" since the beginning of IVF.

Morphology has been a very obvious parameter to assess embryos because it provides a chance for their evaluation from the oocyte stage, all the way to the blastocyst stage. Thus, in the first era of IVF, there was a number of studies that evaluated this parameter and associated morphology with IVF success rates. On the other hand, some researchers stated that the slight increase in pregnancy rates during IVF treatment was most likely a result of better practice in the laboratory than morphologic evaluation $^{(3)}$. Due to the limitations of morphologic evaluation, several researchers investigated adjunctive non-invasive approaches for the assessment of the embryo, such as metabolic parameters ${ }^{(4)}$.

Raman spectroscopy is a vibrational technique that has been used in the field of metabolomics, as well as other techniques such as near-infrared (NIR) spectroscopy, mass spectroscopy, and various others. Raman techniques use a laser to gather vibrational strokes or anti-strokes together with vibrations from the analyzed molecules. Laser-illuminated samples produce scattered light. The amount of light absorbed at a number of vibrational frequencies is then calculated. In the field of metabolomics, one advantage of the Raman technique is that evaluation of liquid samples is straightforward because water gives out weak signals.

The purpose of the present study was to predict the reproductive potential of embryos through Raman spectroscopy evaluation of the spent culture media, as well as conventional morphologic evaluation. We hypothesized that adding Raman spectroscopy to morphologic evaluation would predict better results than those of conventional morphologic evaluation alone.

\section{Materials and Methods}

\section{Patients}

Women of reproductive age (18 to 35 years) who were treated for unexplained infertility in the Infertility Clinic of İstanbul University Faculty of Medicine (İstanbul, Turkey) were invited to participate in this prospective study. Inclusion criteria for the diagnosis of unexplained infertility were as follows: (1) duration of infertility for $>1$ year; (2) confirmation of regular menstrual cycle, (2) hysterosalpingogram-confirmed presence of normal tubal patency; (3) normal day-3 hormonal panel of follicle-stimulating hormone and estradiol, and total antral follicle count more than 7 (4); normal semen analysis results according to the 2010 World Health Organization criteria( ${ }^{(3)}$; (5) planned to undergo IVF/intracytoplasmic sperm injection (ICSI) treatment; and (6) planned to undergo day-3 embryo transfer. This study was approved by Ethics Committee of İstanbul University Faculty of Medicine (2015) and informed consent was received from all participants.

All patients received the same ovulation stimulation and monitoring protocols as previously described ${ }^{(5)}$. In brief, the patients underwent ovarian stimulation with a conventional gonadotropin-releasing hormone antagonist protocol.

After oocyte retrieval, cumulus complexes were isolated in the embryology laboratory and mechanically stripped. Afterwards, oocytes were put into separate $50 \mathrm{~mL}$ of culture (Sagew, Quinn's advantage protein plus cleavage medium, Cooper Surgical, Inc., Trumbull, CT, USA). The same culture was used in all embryos. Conventional ICSI was used in all patients according to our laboratory's process. After the presence of fertilization was identified on day-2 and day-3, as assessed by morphologic evaluation, developed embryos were put into separate $50 \mathrm{~mL}$ of culture until the cleavage stage. Throughout the study, standard tri-gas incubators that provided a $5 \%$ oxygen environment were used and all embryos were cultured in separate media.

\section{Morphologic evaluation}

Grade- 1 embryos were transferred and analyzed according to the morphologic classification as established by Depa-Martynow et al. ${ }^{(6)}$. Grade- 1 was considered as embryos with $\geq 7$ blastomeres similar in shape and with $<20 \%$ of cytoplasmic fragmentation.

\section{End-point}

Clinical pregnancy was the primary outcome of the study, which was defined as the presence of a fetal heartbeat using vaginal ultrasound at 6 weeks of amenorrhea. 


\section{Study design}

After the embryos were removed from the culture and prepared for transfer, the spent culture media were loaded into separate labeled cryovials (Nunc Intermed, Kamstrup, Denmark), and stored at $-80{ }^{\circ} \mathrm{C}$ after snap-freezing in liquid nitrogen. Cryovials were shipped on dry ice to the Raman Spectroscopy Laboratory at İstanbul Technical University (İstanbul, Turkey).

\section{Raman spectroscopy}

The thirty-one samples of 31 patients that were shipped to the Raman Spectroscopy Laboratory for measurement were kept at room temperature for a few minutes and then poured into custom-designed disk-shaped sample cells. The liquid samples were filled in a volumetric cylinder with a diameter of $1.6 \mathrm{~mm}$ and length of $6 \mathrm{~mm}$. These cells allowed small volumes with a reservoir of $30 \mu \mathrm{L}$ and consequently resulted in a long optical path for Raman scattering. The samples were exposed to a single longitudinal mode, $785 \mathrm{~nm}$ diode laser, whose output power was $100 \mathrm{~mW}$. Inelastically-scattered photons were collected with a lens (scattering in 1800 geometry) and then focused into the 100- $\mu \mathrm{m}$ entrance slit of a spectrograph with another lens. The inserted photons were dispersed with a grating $(600 \mathrm{l} / \mathrm{mm})$ according to the wavelengths in the spectrograph and were imaged on a charge-coupled device (CCD) camera.

The spectra to be formed on the CCD camera, which were the multiple images of the entrance slit, were registered. Measurements were performed sequentially over 10 minutes. After a cleaning procedure, a distilled water spectrum was measured as background before every measurement in the same sample cell. A toluene spectrum was measured after every spent culture measurement in order to check laser stability and to have a reference for Raman calibration.

\section{Spectral and statistical analyses}

The Raman spectra were preprocessed using homemade software written on MATLAB and Simulink software (Mathworks, Natick, MA, USA). The spectral analysis preprocess steps are summarized in Figure 1. In brief, the spectra were first cleaned of unwanted cosmic ray peaks. After calibration of the wavenumbers, water spectra were subtracted from the embryo culture measurements as background correction. The residual fluorescence background profile of each spectrum was corrected using a third order polynomial and normalized to their maximum intensity.

Band component analysis was applied on the preprocessed spectra for 815-1065 $\mathrm{cm}^{-1}$ and $1140-1500 \mathrm{~cm}^{-1}$ regions using Gaussian line profiles. The bands were statistically analyzed in view of the pregnancy rates. Each band was tested using the Mann-Whitney U test. Only the band ratio of 900/940 $\mathrm{cm}^{-1}$ was statistically significant $(\mathrm{p}<0.5)$ (Figure 2$)$.

Principal component analysis (PCA) together with quadratic discriminant analysis (QDA) were applied to the measurements for regions containing 900 and $940 \mathrm{~cm}^{-1}$ bands. The numbers of variables were picked as low as possible because PCA is affected by low sample numbers. The analysis was performed for a partial region of the spectra between 890 and $950 \mathrm{~cm}^{-1}$ where the most significant bands found in the band component analysis were located. The first two principal components were used as inputs for QDA analysis. A leave-one-out cross validation was applied to the QDA classifiers in order to obtain the best model. Receiver operating characteristic (ROC) analysis was performed on the QDA classifiers to test the accuracy of the analysis and to find a cut-off value between the two groups.

A sample size calculation was not conducted a priori because previous studies reported no significant differences between groups that were analyzed with conventional morphology and spectroscopic methods ${ }^{(7)}$.

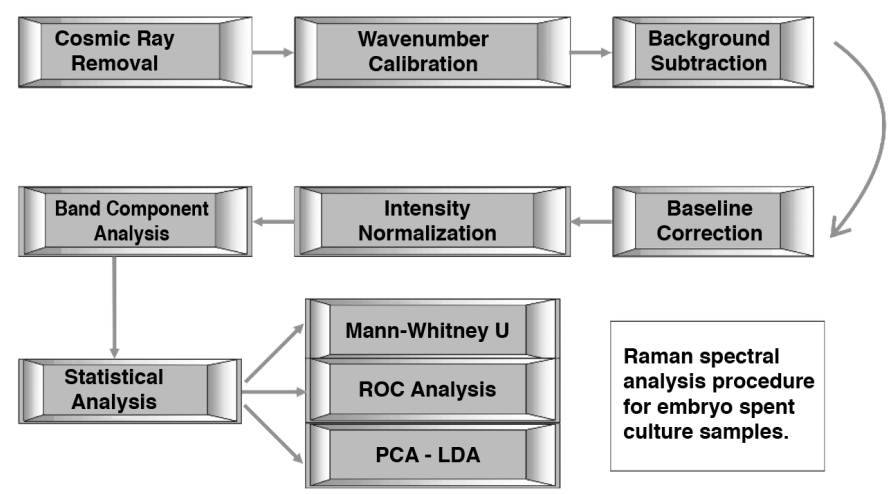

Figure 1. Raman spectral analysis procedure for embryo culture samples

ROC: Receiver operating characteristic, PCA: Principal component analysis, LDA: Linear discriminant analysis

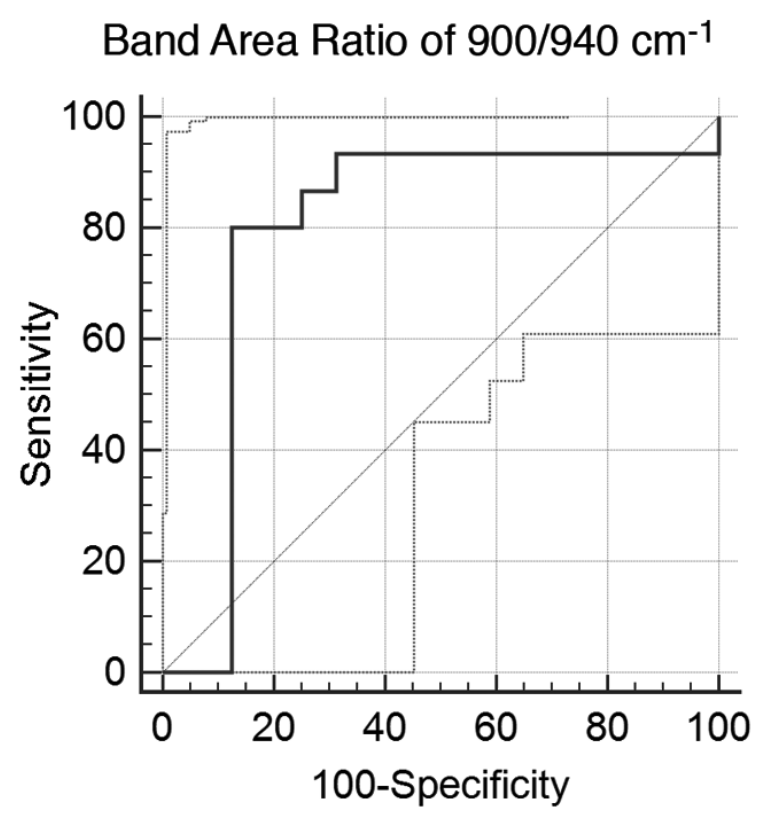

Figure 2. Receiver operating characteristic analysis was made for the band area of 900/940 $\mathrm{cm}^{-1}$. The faint lines show the 95\% confidence interval 


\section{Results}

Thirty-one spent embryo culture media from 31 patients who met the inclusion criteria of the study were preprocessed.

The averages of Raman spectra were calculated for the pregnant and non-pregnant groups. The average spectra are demonstrated in Figure 3 for group comparison. The spectra show no clear distinction but was shifted for better visualization between the samples of patients whose embryos developed to pregnancy or not.

The similarity between the groups described above underscores the need for sophisticated statistical methods such as Raman spectral analysis. We applied QDA after PCA for the region between 890 and $950 \mathrm{~cm}^{-1}$. The score plot of this analysis is shown in Figure 4. Each discriminant line is a parabola that maximizes the between-group distance and minimizes the within-group distance because QDA is a discriminant analysis method that uses second order polynomial function.

The accuracy of PCA-QDA analysis was tested with an additional ROC analysis. The curve obtained from the analysis is shown in Figure 5. ROC analysis was performed and a threshold of 0.4007 (band area ratio) was found. This curve shows that the optimal specificity and sensitivity of this accuracy ROC analysis was $80.25 \%$ and $87.50 \%$, respectively.

Fifteen patients were clinically pregnant, and 16 patients were clinically non-pregnant (Table 1). Clinical pregnancy was predicted using Raman spectroscopy in 93\% (14/15) of clinically pregnant patients, and in $62.5 \%$ (10 out of 16) of clinically non-pregnant patients. The sensitivity of the Raman spectroscopic analysis was $93 \%$ and the specificity was $62.5 \%$.

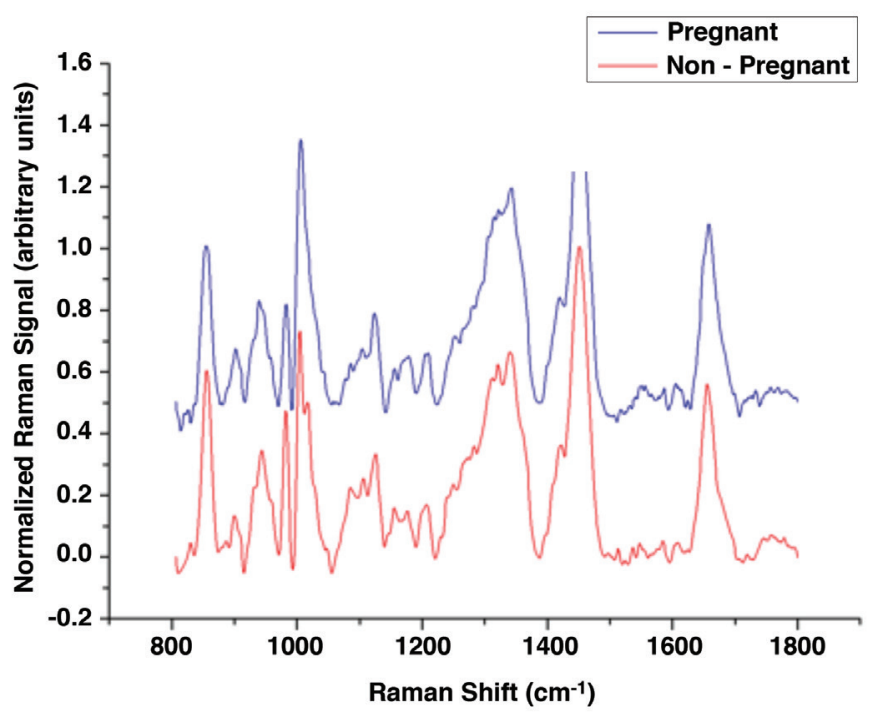

Figure 3. Raman spectra of two selected samples are demonstrated. The corresponding spectra of embryos that developed to pregnancy were manually shifted for better visualization

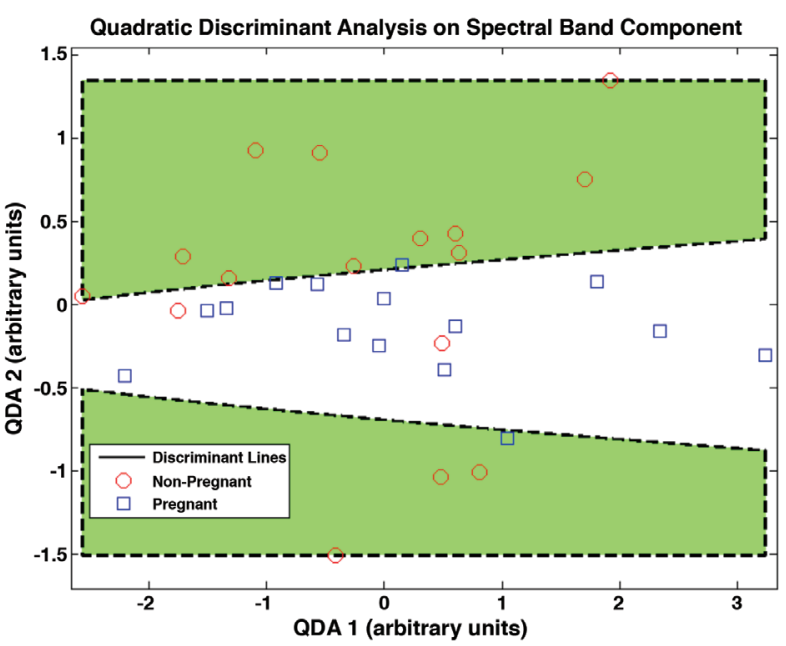

Figure 4. Quadratic discriminant analysis on the band area ratios obtained from band component analysis of the Raman spectra of 31 samples. Discriminant lines were calculated using home-made software that minimizes within-group distances and maximizes between-group distances

QDA: Quadratic discriminant analysis

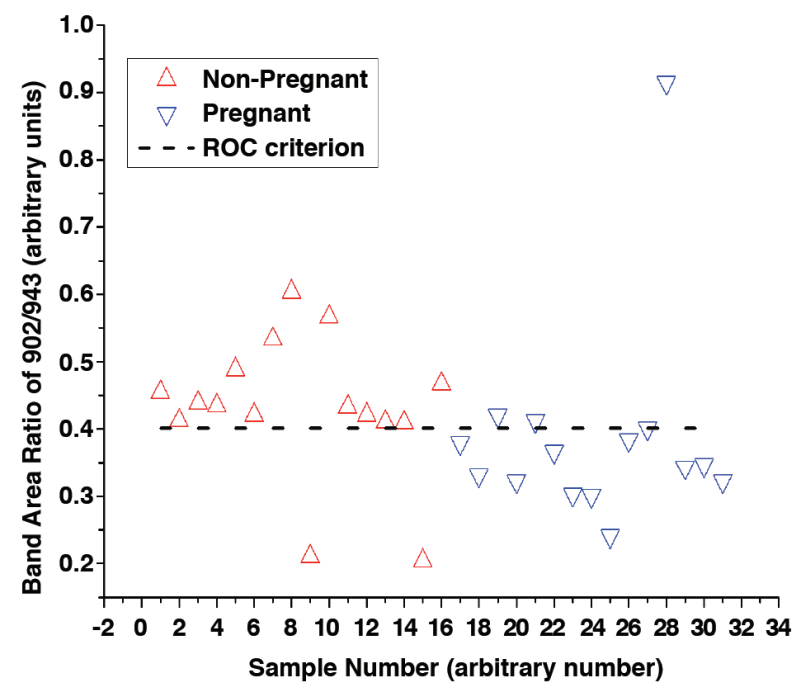

Figure 5. Receiver operating characteristic analysis was performed and a threshold of 0.4007 was found

ROC: Receiver operating characteristic

Table 1. Clinical pregnancy rates according to conventional morphologic evaluation and Raman spectra analysis

\begin{tabular}{lll}
\hline & $\begin{array}{l}\text { Patients predicted } \\
\text { to be pregnant } \\
\text { according Raman } \\
\text { spectra, n (\%) }\end{array}$ & $\begin{array}{l}\text { Patients predicted } \\
\text { to be non-pregnant } \\
\text { according Raman } \\
\text { spectra, n (\%) }\end{array}$ \\
$\begin{array}{lll}\text { Clinically pregnant } \\
\text { patients, n (\%) }\end{array}$ & $14(93)$ & $1(7)$ \\
$\begin{array}{l}\text { Clinically non-pregnant } \\
\text { patients, n (\%) }\end{array}$ & $6(37.5)$ & $10(62.5)$
\end{tabular}




\section{Discussion}

The present study identified that adding Raman spectroscopic analysis of spent embryo culture media revealed that this approach may predict clinical pregnancy as an adjunct to morphologic evaluation.

Currently, conventional morphologic evaluation is the most commonly used approach in assessing embryo quality worldwide. It has been used since the beginning of IVF, first as a tool to explain embryo development ${ }^{(8)}$, and then to select the embryo with the highest implantation transfer potential ${ }^{(9-13)}$. Morphologic evaluation is based on the embryologist; therefore, embryo scores can vary considerably because it is still a somewhat subjective matter ${ }^{(14)}$.

Metabolomics is an emerging "omics" science that has evolved from proteomics, genomics and transcriptomics. It systematically analyzes the inventory of metabolites. These metabolites are representatives of functional phenotypes at a cellular level. Within this context, researchers focused on the composition of the culture media. The subsequent step was the metabolomic analysis of what embryos use from the culture media and release during their development and to understand if there was a correlation with successful or unsuccessful implantation to the maternal uterus ${ }^{(15)}$.

Seli et al. ${ }^{(16)}$ documented the first proof-of-concept study, which correlated the metabolome of the spent embryo culture media with embryo viability using Raman spectroscopy. The mean spectrum of embryos that did not implant was compared with the mean spectrum of embryos that implanted successfully. In a study by Scott et al. ${ }^{(17)}$, the mean spectrum was validated by analyzing spent embryo culture from a different IVF center that used a different type of culture. Further studies with either Raman and/or NIR spectroscopy argued that the metabolomic profile of the spent embryo culture media was a parameter that was independent of embryo morphology ${ }^{(18-24)}$. The present study is in line with these findings and shows that metabolomic evaluation of spent embryo culture media alone can predict reproductive potential as efficiently as conventional morphologic evaluation of the embryo.

Interestingly, despite the promise of metabolomic evaluation, the use of Raman spectroscopy and/or other techniques such as NIR and mass spectroscopy have limited clinical presence. There are a few potential explanations for these limitations. Currently, the equipment used for these spectroscopic techniques are expensive and require dedicated specialists. Moreover, prompt results are needed during embryo transfer in clinical practice and the applicable information gathered from spectroscopic techniques still requires time. If we look specifically at Raman spectroscopy for the purpose of metabolomic evaluation, it provides weak signal intensity, which may be a drawback when sample concentrations are low. Enhancement methods such as surface-enhanced Raman spectroscopy (SERS) or resonance Raman spectroscopy (RRS) can be used to overcome this limitation. On the other hand, RRS may damage the sample and produce broad background in the spectra; therefore, it may shield information from the spectra. Although SERS suffers from repeatability, it is a developing method and may be useful for future studies. However, it is important to note that even with the aforementioned drawbacks, Raman spectroscopy alone still produced results that were comparable to conventional morphologic evaluation in the present study. Hence, if these drawbacks were to be overcome in future studies, metabolomic evaluation could provide a more objective approach to the current morphologic evaluation and possibly result in becoming a more accurate technique with increased reproductive outcomes.

\section{Study Limitations}

A limitation of the study was its small sample size. We wanted to create an ideal design by only including single embryo transfer. Due to the financial aspects of IVF treatment and psychological burden, single embryo transfer is only occasionally feasible. Also, Raman spectroscopy equipment use and evaluation of embryo culture media required time to give results that could be utilized in routine clinic practice.

\section{Conclusion}

Existing embryo assessment relies heavily on the morphologic evaluation of the embryo by an embryologist. Furthermore, this subjective method does not provide sufficient specificity or sensitivity to produce desirable pregnant rates for patients receiving IVF treatment. Metabolomic evaluation of spent embryo culture media is an emerging technique with promising objective results. However, there is clearly room for improvement in the exact spectroscopic technique used for metabolomic evaluation. Moreover, it has to be adequately validated. Hence, this approach still remains experimental and its application has not translated into the clinical setting. Further randomized control trials with improved spectroscopic techniques are needed to document the potential benefit from the use of metabolomic evaluation alone or as an adjuvant approach to the conventional morphologic evaluation.

\section{Acknowledgement}

We would like to thank David F. Chapman, BSc, for editing the language of the manuscript. This research received funding from the Scientific Research Projects Coordination Unit of İstanbul University (grant number: 22501).

\section{Ethics}

Ethics Committee Approval: This study was approved by Ethics Committee of İstanbul University Faculty of Medicine (2015).

Informed Consent: Consent form was filled out by all participants.

Peer-review: External and internal peer-reviewed.

\section{Authorship Contributions}

Concept: E.B., G.B., Design: E.B., F.B., Data Collection or Processing: H.Y., S.B., Analysis or Interpretation: N.B., U.P., Literature Search: F.S., E.B., Writing: E.B., U.P. 
Conflict of Interest: No conflict of interest was declared by the authors.

Financial Disclosure: This research received funding from the Scientific Research Projects Coordination Unit of İstanbul University (grant number: 22501).

\section{References}

1. Multiple gestation pregnancy. The ESHRE Capri Workshop Group. Hum Reprod 2000;15:1856-64.

2. Centers for Disease Control and Prevention ASfRM, Society for Assisted Reproductive Technology. 2013 Assisted Reproductive Technology Fertility Clinic Success Rates Report. In. Atlanta (GA): US Dept of Health and Human Services, 2015.

3. WHO. WHO laboratory manual for the examination and processing of human semen. Geneva, Switzerland, 2010.

4. Botros L, Sakkas D, Seli E. Metabolomics and its application for noninvasive embryo assessment in IVF. Mol Hum Reprod 2008;14:67990.

5. Bastu E, Mutlu MF, Yasa C, Dural O, Nehir Aytan A, Celik C, et al. Role of Mucin 1 and Glycodelin A in recurrent implantation failure. Fertil Steril 2015;103:1059-64.e2.

6. Depa-Martynow M, Jedrzejczak P, Pawelczyk L. Pronuclear scoring as a predictor of embryo quality in in vitro fertilization program. Folia Histochem Cytobiol 2007;45(Suppl 1):S85-9.

7. Vergouw CG, Heymans MW, Hardarson T, Sfontouris IA, Economou $\mathrm{KA}$, Ahlstrom A, et al. No evidence that embryo selection by nearinfrared spectroscopy in addition to morphology is able to improve live birth rates: results from an individual patient data meta-analysis. Hum Reprod 2014;29:455-61.

8. Edwards RG, Purdy JM, Steptoe PC, Walters DE. The growth of human preimplantation embryos in vitro. Am J Obstet Gynecol 1981;141:408-16.

9. Alpha Scientists in Reproductive Medicine and ESHRE Special Interest Group of Embryology. The Istanbul consensus workshop on embryo assessment: proceedings of an expert meeting. Hum Reprod 2011;26:1270-83

10. Desai NN, Goldstein J, Rowland DY, Goldfarb JM. Morphological evaluation of human embryos and derivation of an embryo quality scoring system specific for day 3 embryos: a preliminary study. Hum Reprod 2000;15:2190-6.

11. Hill GA, Freeman M, Bastias MC, Rogers BJ, Herbert CM, Osteen $\mathrm{KG}$, et al. The influence of oocyte maturity and embryo quality on pregnancy rate in a program for in vitro fertilization-embryo transfer. Fertil Steril 1989;52:801-6.

12. Montag M, Liebenthron J, Köster M. Which morphological scoring system is relevant in human embryo development? Placenta 2011;32(Suppl 3):S252-6.
13. Racowsky C, Vernon M, Mayer J, Ball GD, Behr B, Pomeroy KO, et al. Standardization of grading embryo morphology. Fertil Steril 2010;94:1152-3

14. Baxter Bendus AE, Mayer JF, Shipley SK, Catherino WH. Interobserver and intraobserver variation in day 3 embryo grading. Fertil Steril 2006;86:1608-15.

15. Gardner DK, Lane M, Stevens J, Schoolcraft WB. Noninvasive assessment of human embryo nutrient consumption as a measure of developmental potential. Fertil Steril 2001;76:1175-80.

16. Seli E, Sakkas D, Scott R, Kwok SC, Rosendahl SM, Burns DH. Noninvasive metabolomic profiling of embryo culture media using Raman and near-infrared spectroscopy correlates with reproductive potential of embryos in women undergoing in vitro fertilization. Fertil Steril 2007;88:1350-7.

17. Scott R, Seli E, Miller K, Sakkas D, Scott K, Burns DH. Noninvasive metabolomic profiling of human embryo culture media using Raman spectroscopy predicts embryonic reproductive potential: a prospective blinded pilot study. Fertil Steril 2008;90:77-83.

18. Ahlstrom A, Wikland M, Rogberg L, Barnett JS, Tucker M, Hardarson T. Cross-validation and predictive value of near-infrared spectroscopy algorithms for day-5 blastocyst transfer. Reprod Biomed Online 2011;22:477-84

19. Hardarson T, Ahlstrom A, Rogberg L, Botros L, Hillensjo T, Westlander $G$, et al. Non-invasive metabolomic profiling of Day 2 and 5 embryo culture medium: a prospective randomized trial. Hum Reprod 2012;27:89-96

20. Kirkegaard K, Svane AS, Nielsen JS, Hindkjaer JJ, Nielsen NC, Ingerslev HJ. Nuclear magnetic resonance metabolomic profiling of Day 3 and 5 embryo culture medium does not predict pregnancy outcome in good prognosis patients: a prospective cohort study on single transferred embryos. Hum Reprod 2014;29:2413-20.

21. Seli E, Bruce C, Botros L, Henson M, Roos P, Judge K, et al. Receiver operating characteristic (ROC) analysis of day 5 morphology grading and metabolomic Viability Score on predicting implantation outcome. J Assist Reprod Genet 2011;28:137-44.

22. Seli E, Vergouw CG, Morita H, Botros L, Roos P, Lambalk CB, et al. Noninvasive metabolomic profiling as an adjunct to morphology for noninvasive embryo assessment in women undergoing single embryo transfer. Fertil Steril 2010;94:535-42.

23. Vergouw CG, Botros LL, Roos P, Lens JW, Schats R, Hompes PG, et al. Metabolomic profiling by near-infrared spectroscopy as a tool to assess embryo viability: a novel, non-invasive method for embryo selection. Hum Reprod 2008;23:1499-504.

24. Vergouw CG, Kieslinger DC, Kostelijk EH, Botros LL, Schats R, Hompes PG, et al. Day 3 embryo selection by metabolomic profiling of culture medium with near-infrared spectroscopy as an adjunct to morphology: a randomized controlled trial. Hum Reprod 2012;27:2304-11. 